\title{
NO-released Zinc Supports the Simultaneous Binding of Raf-1 and PKC $\gamma$ Cysteine-Rich Domains to HINT1 Protein at the Mu-Opioid Receptor
}

\author{
María Rodríguez-Muñoz, Elena de la Torre-Madrid, ${ }^{2}$ Pilar Sánchez-Blázquez,, ${ }^{1,2}$ and Javier Garzón $n^{1,2}$
}

\begin{abstract}
In the brain, the mu-opioid receptor (MOR) activates neural nitric oxide synthase (nNOS) through the PI3K/Akt pathway. The resulting nitric oxide (NO) enhances the function of the glutamate $N$-methyl-D-aspartate receptor (NMDAR)/calcium and calmodulin-dependent serine/threonine kinase (CaMKII), which subsequently diminishes MOR signaling strength. Because the ERK1/2 cascade is implicated in opioid tolerance, we analyzed the role of morphine-generated NO in this negative regulation. We found that NO-released endogenous zinc ions recruit the Ras/Raf-1/ERK1/2 cassette to histidine triad nucleotide-binding protein 1 (HINT1). A-Raf and B-Raf showed little or no MOR association. The zinc ions bridge the Raf-1 cysteine-rich domain (CRD) with HINT1 at the MOR C-terminus. Morphine also recruits PKC $\gamma$ via NO/zinc to the MOR-HINT1 complex. Both Raf-1 and PKC $\gamma$ CRDs bind simultaneously to HINT1, enabling PKC $\gamma$ to enhance Raf-1 function to intensify MEK/ERK1/2 activation. Thus, through attached HINT1, the MOR facilitates the cross-talk of two NO- and zinc-regulated signal-transduction pathways, PKC/Src and Raf-1/ERK1/2, implicated in the negative control of morphine effects. This study reveals new aspects of ERK1/2 regulation by the MOR without requiring the transactivation of a receptor tyrosine kinase. Antioxid. Redox Signal. 14, 2413-2425.
\end{abstract}

\section{Introduction}

O PIOIDS are probably the most effective drugs in attenuating nociceptive perception, and they are the analgesics of choice to relieve intense chronic pain. These substances exert this positive action by binding to specific $\mathrm{mu}$, delta, and kappa receptors in the nervous system, members of the GPCR (G protein-coupled receptor) family. Pharmacologic studies performed on genetically modified mice indicate that morphine and its derivatives induce antinociception through the mu-opioid receptor (MOR) (13), which is coupled to $\mathrm{Gi}, \mathrm{Go}, \mathrm{Gz}$, and Gq/11 proteins, and that activation of this receptor regulates diverse effectors, such as inwardly rectifying potassium channels; voltage-activated calcium channels; adenylyl cyclase; phospholipases; the MAPK cascade; the PI3K/Akt/nNOS pathway; the Nmethyl-D-aspartate glutamate receptor (NMDAR)/CaMKII cascade; and so on (36). Unfortunately, repeated administration of opioid analgesic drugs provokes a progressive decrease in their potency (tolerance), higher doses then being required to obtain the expected outcome, with the risk of augmenting the adverse effects and of establishing physical dependence.
The most common mechanism that produces GPCR desensitization involves the phosphorylation of intracellular residues by G-protein receptor kinases (GRKs), which is followed by arrestin binding and subsequent internalization of the receptor molecule. However, although opioids such as etorphine and [D-Ala ${ }^{2}, \mathrm{~N}-\mathrm{Me}-\mathrm{Phe}^{4}$, and $\mathrm{Gly}^{5}$-ol]-encephalin (DAMGO) stimulate efficient internalization of the MOR, strong tolerance to morphine analgesia develops but without receptor internalization $(9,31)$. A series of studies revealed that the activity of the NMDAR/NO/CaMKII cascade in neural tissue is mostly responsible for the development of tolerance to morphine antinociception (9). This negative regulation of MOR-mediated effects by NMDAR provides the basis for the clinical efficacy of NMDAR antagonists in preventing, and even rescuing, morphine analgesia from tolerance (14).

A series of signaling proteins participate in this MORNMDAR cross-talk, including HINT1, a member of the histidine triad (HIT) protein family. HINT1 is a 126-amino acid protein of about $14 \mathrm{kDa}$ that exists as a homodimer (23). HINT1 binds to the C terminus of the MOR (33), and it connects this receptor to GTPase activating proteins (GAPs) of receptor-activated GaGTP subunits, the RGS17(Z2) and

\footnotetext{
${ }^{1}$ CIBER Mental Health (CIBERSAM), ISCIII, Madrid, Spain.
}

${ }^{2}$ Neuropharmacology, Cajal Institute, CSIC, Madrid, Spain. 
RGS20(Z1) proteins (33). On morphine challenge, this HINT1/RGSZ complex recruits inactive PKC $\gamma$ to the MOR C terminus, a process mediated by zinc ions (32). The HINT1 protomer contains a row of three histidines that are separated by hydrophobic amino acids, which are crucial for its zincdependent interaction with the cysteine-rich domain (CRD) of the PKC $\gamma$ C1 regulatory domain (32). The free zinc ions required are initially provided by the morphine-induced activation of the PI3K/Akt/nNOS pathway (36) and the subsequent action of $\mathrm{NO}$ on intracellular zinc stores (18). At late postmorphine intervals, MOR-induced NMDAR activation facilitates the translocation of zinc ions from the presynaptic terminal into the postsynaptic neuron, contributing to the recruitment of PKC $\gamma$ to the MOR environment $(22,36)$. The PKC $\gamma$ activates the tyrosine kinase Src (35), and both PKC and Src kinases produce the sustained potentiation of NMDAR calcium currents $(2,35)$. Subsequently, the activation of CaMKII is essential for the NMDAR-dependent development of tolerance to the analgesic effects of morphine $(9$, $37)$. In addition, the production of morphine analgesic tolerance also requires ERK1/2 activation $(3,29)$, which probably contributes to the sensitization to pain by increasing the activity of glutamate NMDAR (11).

Interestingly, some functional and structural analogies exist between $\mathrm{PKC} \gamma$ and the Raf kinase that acts upstream of ERK1/2. Raf kinases are ubiquitous serine/threonine kinases that play critical roles in mediating the activation of the ERK1/2 cascade by the small G protein, p21 Ras (25).

The $\mathrm{C} 1$ regulatory domain of all $\mathrm{PKC}$ isozymes is a CRD that is organized as a tandem $\mathrm{C} 1 \mathrm{~A}$ and $\mathrm{C} 1 \mathrm{~B}$ repeat, coordinating the binding of zinc as well as that of phorbol esters or diacylglycerol (DAG) $(17,27)$. CRD motifs also are present in the regulatory region of the Raf kinases (26). All Raf kinases possess three highly conserved regions, designated C1, C2, and C3 (20), whereas the catalytic domain of Raf kinase is in the C-terminal half of the protein (C3). The amino terminus of Raf contains two conserved regions (C1 and $\mathrm{C} 2$ ) that negatively regulate the kinase domain. The $\mathrm{C} 1$ region consists of two distinct structural modules called the Ras-binding domain $(\mathrm{RBD})$ and the $\mathrm{CRD}$. The CRD contains two zinc-finger motifs resembling the $\mathrm{C} 1$ domain of the conventional protein kinase C. It is notable that the Raf CRD does not bind DAG, even though it does interact with phosphatidylserine (10).

Therefore, morphine-induced activation of PKC and ERK1/ 2 is essential for the NMDAR-dependent development of tolerance to the analgesic effects of this opioid. Since the initial report associating PKC with MOR-dependent enhancement of NMDAR function (2), other elements have been identified that bridge the gap between both receptors, as well as NO redox signaling $(32,35,36)$. With respect to the ERK1/2 pathway, its activation promotes the surface expression of AMPAR-containing GluR1/GluR2L subunits, which enhance NMDAR function by long-term potentiation (LTP) of the postsynapse (50). However, little is known about the molecular processes implicated in the morphine-evoked activation of this MAPK. Because PKC increases the activity of the ERK1/2 cascade by acting directly on Raf kinases (16), we investigated whether the HINT1 complex can act as an adaptor coupling the PKC and Raf kinase pathways under the regulation of the MOR. We also examined the influence of the zinc metal ion in this process, and of the nNOS/NO cascade as the physiologic source of these ions.

\section{Materials and Methods}

\section{Zinc-microfluorescence imaging in CD1 mouse striatal slices}

Transverse $200-\mu \mathrm{m}$ brain slices were prepared according to standard procedures. The slices were placed on the thermostatically heated stage of an inverted microscope and bathed in artificial cerebrospinal fluid: $124 \mathrm{NaCl}, 1.75 \mathrm{KCl}, 1.3$ $\mathrm{MgSO}_{4}, 2.4 \mathrm{CaCl}_{2}, 1.25 \mathrm{KH}_{2} \mathrm{PO}_{4}, 26 \mathrm{NaHCO}_{3}$, and 10 dextrose $(\mathrm{mM}), \mathrm{pH}$ 7.4. The temperature inside the piezo-electrically controlled incubation chamber (Life Imaging Services, Basel, Switzerland) was held at $32^{\circ} \mathrm{C}$ in an atmosphere of $95 \% \mathrm{O}_{2} /$ $5 \% \mathrm{CO}_{2}$.

For intracellular $\mathrm{Zn}^{2+}$ imaging, the slices were preloaded with $50 \mu M$ cellular permeable Newport Green DCF diacetate (N7991; Invitrogen, Carlsbad, CA), 0.1\% pluronic acid (P3000MP, Invitrogen), and $0.5 \%$ dimethyl sulfoxide for $1 \mathrm{~h}$, as described in a previous study (22). Saline or morphine $(10 \mu M)$ was added to the wells. The MOR antagonist naloxone was added $(30 \mu \mathrm{M}) 10 \mathrm{~min}$ before the morphine, and the nNOS inhibitor L-NNA $(100 \mu \mathrm{M})$ was added $20 \mathrm{~min}$ before the morphine. Images were obtained with confocal microscopy by using a Leica DMIII 6000 CS confocal fluorescence microscope equipped with a TCS SP5 scanning laser (excitation, $488 \mathrm{~nm}$; emission, $498-520 \mathrm{~nm}$ ) through a $10 \times 0.4 \mathrm{HC}$ PL APO objective. The images shown in Fig. 4 were collected after $30 \mathrm{~min}$.

\section{Preparation and solubilization of PAG synaptoneurosome-enriched fraction}

MOR immunoprecipitation and co-precipitation of associated proteins. Procedures involving mice strictly followed the guidelines of the European Community for the Care and Use of Laboratory Animals (Council Directive 86/609/EEC) and Spanish Law (RD 1201/2005) regulating animal research. The experimental protocols were reviewed and approved by the Committee for Animal Experimentation at the CSIC.

Experimental tissue was obtained from male albino CD1 mice (Charles River, Barcelona, Spain) weighing 22-27 g. For the immunoprecipitation studies, the periaqueductal gray matter (PAG) from eight mice were pooled for each postmorphine interval. The assays were repeated at least twice on samples obtained from different mice that had received an identical opioid treatment and that had been killed at the same interval after opioid administration. The methods used to prepare the PAG synaptosomal fraction have been described elsewhere $(31,32)$. The affinity-purified IgGs against the extracellular domains, $\mathrm{N}$ terminus (NT), and second external loop (2EL) of murine MOR were labeled with biotin (Pierce 21217 and 21339). The MOR was immunoprecipitated from solubilized membranes, as described in earlier work (31, 37). The immunoprecipitated proteins were resolved with SDS/polyacrylamide gel electrophoresis (PAGE) in $10 \mathrm{~cm} \times$ $10 \mathrm{~cm} \times 1.5$-mm gel slabs (7-14\% total acrylamide concentration, $2.6 \%$ bisacrylamide cross-linker concentration). The PAG structures from eight mice (corresponding to an interval after morphine) yielded enough immunoprecipitated MOR and associated proteins to load approximately four gel lanes. The separated proteins were then transferred onto 0.2- $\mu \mathrm{m}$ PVDF membranes and probed with the selected antibodies in DecaProbe chambers (PR 150; Hoefer-GE, Barcelona, Spain). 
Spectrophotometric detection of zinc released from PAG synaptosomes. Samples $(0.5 \mathrm{ml}$ total volume $)$ were prepared by adding $100 \mu \mathrm{l}$ of PAG membrane suspension, vehicle, or NO donor to $400 \mu \mathrm{l}$ of Hepes buffer [25 mM; pH 7.8; treated with Chelex-100 resin (BioRad)]. Calibration samples were prepared from $\mathrm{ZnCl}_{2}(100 \mathrm{mM}$ ) solution (Sigma 39059) and Hepes buffer. For blanks, the metal solution was substituted with Chelex100-treated water. Complexation was initiated by the addition of the zinc chelator Zincon (Sigma 96440) (stock solution, $1.6 \mathrm{mM}$ in $\mathrm{NaOH}, 1 \mathrm{M}$ ) to reach a final concentration of $40 \mu \mathrm{M}$. Absorbance $(600 \mathrm{~nm})$ was recorded after $20 \mathrm{~min}$ of sample incubation at room temperature (RT) on a BioChrom Ultrospec 2100 spectrophotometer (Cambridge, UK).

\section{Detection of signaling proteins}

Western blots were probed with the following antibodies: affinity-purified IgG raised against extracellular domains of murine MOR (aa NT 2-16, 2EL 208-216) (1:3,000); anti-PKC $\gamma$ (1:1,000; Abcam ab4145); anti-Raf-1 (1:1,000; BD Biosciences 610152); anti-A-Raf (1:1,000; BD 610074); anti-B-Raf $(1: 1,000$; BD 612375); anti-Ras (1:1,000; BD 610001); anti-Rap1 (1:1,000; BD 610195); anti-pan ERK (1:5,000; BD 610124); anti-phosphoERK (T202 + Y204) (1:5,000; ab24157); anti-RasGRP2 (1:1,000; aa 591-604 IREEEVQTVEDGVF); anti-RasGRP3 (1:1,000; aa 94-107 GLIRMTEEFREVAS); and nNOS (1:1,000; Santa Cruz sc-1025). All antibodies were diluted in TBS $+0.05 \%$ Tween 20 (TTBS) and incubated with polyvinylidene difluoride (PVDF) membranes (BioRad 162-0176) overnight at $6^{\circ} \mathrm{C}$. The primary antibodies were detected with the corresponding secondary antibodies conjugated to horseradish peroxidase and diluted to 1:10,000. Antibody binding was visualized with the ECL Plus Western Blotting Detection System (RPN2132; Amersham Biosciences), and chemiluminescence was recorded with the ChemiImager IS-5500 system (Alpha Innotech, San Leandro, CA). Densitometry was performed by using Quantity One Software (BioRad) and expressed as the integrated volume (average optical density of the pixels within the object area $\left./ \mathrm{mm}^{2}\right)$.

\section{Studies conducted with recombinant proteins}

The interaction of HINT1 (200nM) with either PKC $\gamma$ (100 nM) or Raf-1 (100 nM) (Abnova H00005894) was studied. A similar assay was conducted to analyze the interaction between HINT1 and the catalytic domain of PKC $\gamma$ (Calbiochem 539513) or Raf-1 (GenScript Z02210). The interaction of HINT1 with H-Ras (Calbiochem 553329) also was evaluated. Zinc was removed from recombinant proteins by $60 \mathrm{~min}$ of incubation at room temperature in a buffer containing $10 \mathrm{mM}$ Hepes, $\mathrm{pH} 7.5$; $150 \mathrm{mM} \mathrm{NaCl} ; 5 \mathrm{mM}$ EDTA; $200 \mu \mathrm{M}$ DTT, and $1 \mathrm{mM}$ $N, N, N^{\prime}, N^{\prime}$-tetrakis(2-pyridylmethyl) ethylenediamine (TPEN; Fluka WA16827). The buffer was then exchanged with $10 \mathrm{mM}$ Hepes, pH 7.5, $150 \mathrm{mM} \mathrm{NaCl}$, and proteins were concentrated in centrifugal filter devices (10-kDa nominal molecular mass limit; Amicon Microcon YM-10 42407, Millipore). After zinc removal, proteins were incubated either alone (negative control) or together with the GST-tagged protein in $400 \mu \mathrm{l}$ buffer of $10 \mathrm{mM}$ HEPES, pH 7.4, $150 \mathrm{mM} \mathrm{NaCl}$, and $0.005 \%$ Tween 20 for $30 \mathrm{~min}$ at room temperature. After incubation, $40 \mu \mathrm{l}$ of glutathione sepharose (GE 170756 01) was added, and pellets were obtained by centrifugation and washed 3 times, solubilized in $2 \times$ Laemmli buffer, and analyzed with Western blotting.
The possible mutual interference of Raf- 1 and PKC $\gamma$ for their binding to HINT1 protein was studied. The incubation of recombinant HINT (200 nM) with GST-Raf-1 was carried out with increasing amounts of PKC $\gamma$ for $30 \mathrm{~min}$ at room temperature (10 mM Hepes, $\mathrm{pH} 7.4,150 \mathrm{mM} \mathrm{NaCl}, 100 \mu M$ zinc).

\section{In vitro effect of zinc on the recruitment of signaling proteins to MOR: CRD alteration, zinc chelator, and NO generators}

The effect of increasing concentrations of zinc on the association of a series of signaling proteins with MOR was studied in PAG synaptosomal membranes. Zinc chloride (Puratronic, Alfa Aesar 231-592-0) was added, together with biotinylated antiMOR IgGs, and the samples were incubated for $4 \mathrm{~h}$ at $4^{\circ} \mathrm{C}$. In another set of assays, the time-course for $3 \mu \mathrm{M}$ zinc to produce Raf- 1 and PKC $\gamma$ association with the PAG MOR was studied during $30 \mathrm{~min}$ at RT in the absence and presence of TPEN. Subsequently, zinc was removed with centrifugation, and PAG synaptosomal membranes were solubilized in Nonidet P-40 buffer, as previously described $(31,37)$. The solubilized membranes were incubated overnight at $4^{\circ} \mathrm{C}$ with approximately $3 \mu \mathrm{g}$ of biotin (Pierce 21217 and 21339) conjugated primary antibody (affinity-purified IgGs) raised against the murine MOR. The MOR-associated proteins were then separated with SDS-PAGE chromatography and analyzed with Western blots. The PKC inhibitor calphostin C, which binds to and alters the structure of the CRD (Merck-Calbiochem 208725), was added $1 \mathrm{~h}$ before the zinc chloride. The NO generators (S)-nitroso- $\mathrm{N}$ acetylpenicillamine (SNAP; Tocris Bioscience 0598) and ( \pm )(E)-ethyl-2-[(E)-hydroxyimino]-5-nitro-3-hexeneamide (NOR-3 or FK409; Merck-Calbiochem 489530) were incubated with the samples overnight and with the anti-MOR IgGs at $4^{\circ} \mathrm{C}$. SNAP and NOR-3 also were studied for $1 \mathrm{~h}$ at RT. The procedure continued as described earlier. The heavy metal ion chelator TPEN (Fluka WA16827) was added to the solubilized samples together with the zinc chloride.

\section{Animals, intracerebroventricular injection, and evaluation of antinociception}

Male albino CD-1 mice weighing 22-25 g were housed and used strictly in accordance with the guidelines of the European Community for the Care and Use of Laboratory Animals (Council Directive 86/609/EEC). The response of the animals to nociceptive stimuli and the influence of morphine sulfate (Merck, Darmstadt, Germany) were determined by the warm-water $\left(52^{\circ} \mathrm{C}\right)$ tail-flick test. Baseline latencies ranged from 1.5 to $2.0 \mathrm{~s}$, and they were not significantly affected by the inhibitor L-NG-nitroarginine (L-NNA; Tocris 0664) or its solvent. A cut-off time of $10 \mathrm{~s}$ was used to minimize the risk of tissue damage. Antinociception was expressed as a percentage of the maximum possible effect $(\mathrm{MPE}=100 \times$ [test latencybaseline latency]/[cutoff time-baseline latency]). Groups of eight mice were lightly anesthetized with ether and received 10 nmol morphine sulfate (Merck, Darmstadt, Germany) (in a volume of $4 \mu \mathrm{l}$ ) injected into the lateral ventricle. Antinociception was assessed at different time intervals thereafter. Data are expressed as the mean \pm SEM.

A mouse knockout 129SvJ strain with targeted disruption of HINT1 (40) was generously supplied by I.B. Weinstein and J.B. Wang. The genotype was confirmed with PCR analysis of DNA extracted from tail biopsies. 


\section{Statistical significance}

ANOVA, followed by the Student-Newman-Keuls test (SigmaStat; SPSS Science Software, Erkrath, Germany) was performed, and significance was defined as $p<0.05$.

\section{Results}

\section{Morphine stimulates Raf-1 binding to the MOR}

The ICV administration of morphine produces a dose- and time-dependent antinociceptive effect that reaches a maximum at about $30 \mathrm{~min}$ after its injection. The administration of $3 \mathrm{nmol}$ and $10 \mathrm{nmol}$ of the opioid led to peak analgesic effects of about $50 \%$ and $80 \%$ of the maximum analgesic effect that is detected in the thermal tail-flick test (cutoff time of $10 \mathrm{~s}$ ). A remnant effect of about 30\% is observed $90 \mathrm{~min}$ after injection of the higher dose, and postopioid analgesia was no longer detected at $3 \mathrm{~h}$ (Fig. 1B).

The MOR in the midbrain PAG is rather superficial to the aqueduct and is reached by ICV-injected opioids to produce supraspinal antinociception. In this study, the mice were injected with $10 \mathrm{nmol}$ morphine, after which groups of eight animals were killed at different time points of the analgesic time course, and PAG synaptosomal membranes were obtained for the ex vivo determinations. Morphine, during its analgesic time course, promotes MOR-PKC $\gamma$ association. With the ces-

FIG. 1. Morphine recruits Raf-1and PKC $\gamma$ to the MOR. (A) The primary structure of Raf- 1 and of conventional PKC $(\alpha, \beta, \gamma)$. Raf-1: C1-C3 conserved regions; the N-terminal regulatory region contains $\mathrm{C} 1$ and $\mathrm{C} 2$; the $\mathrm{C} 1$ region consists of two subregions: the Ras-binding domain (RBD) and the cysteine-rich domain (CRD); the C-terminal C3 region corresponds to the catalytic domain. PKC: C1-C4 conserved regions; the $\mathrm{N}$-terminus contains the regulatory region with the pseudo substrate (PS); $\mathrm{C} 1$ contains tandem $\mathrm{C} 1 \mathrm{~A}$ and $\mathrm{C} 1 \mathrm{~B}$ cysteine-rich domains (CRDs) that bind zinc and phorbol esters/diacylglycerol; C2 binds phosphatidylserine and calcium; the C-terminal region contains the ATP-binding site (C3) and the kinase domain (C4) that binds the substrate. In both kinases, the $\mathrm{N}$-terminal regulatory domain regulates (inhibits) the activity of the C-terminal catalytic domain. (B) Morphine ( $3 \mathrm{nmol}$ and $10 \mathrm{nmol}$ ) was injected ICV into mice. Data are the analgesic time course determined by the tailflick test. Each data point is the mean \pm SEM, $n=8$ mice. *Significantly different from the preopioid control interval (0 min), $p<0.05$. (C) Ex vivo molecular studies: After $10 \mathrm{nmol}$ ICV morphine, groups of eight mice were killed at the intervals indicated; their PAG were pooled and used for MOR immunoprecipitation and co-precipitation of $\mathrm{PKC} \gamma$, Raf- 1 , and B-Raf. Immunosignals are shown relative to $0 \mathrm{~min}$ (animals not receiving the opioid were attributed an arbitrary value of 1$)$. The $\mathrm{nNOS}$ inhibitor L-NNA $(7 \mathrm{nmol})$ was injected ICV $30 \mathrm{~min}$ before morphine. Open bars, control mice; solid bars, mice receiving L-NNA. Immunoprecipitated MOR signals are the loading control. Each bar is the mean of three assays performed on PAG samples obtained from independent groups of eight mice each. Data are expressed as mean \pm SEM. *Significantly different from the group $0 \mathrm{~min}$, $p<0.05$. Inset: Immunosignals for $\mathrm{PKC} \gamma \quad(78 \mathrm{kDa})$, Raf- 1 $(74 \mathrm{kDa}), \mathrm{B}-\mathrm{Raf}(95 \mathrm{kDa})$, and A-Raf $(68 \mathrm{kDa})$ determined in PAG membranes with the antibodies and dilutions used to detect MOR-associated proteins. sation of analgesia, this association, although reduced, still persisted for several hours (Fig. 1C) (32). The CRD-containing Raf-1 serine and threonine kinase also responded to morphine, increasing its association with the MOR. The A-Raf and B-Raf isoforms, although present in PAG synaptosomes, are seldom associated with MOR in response to morphine.
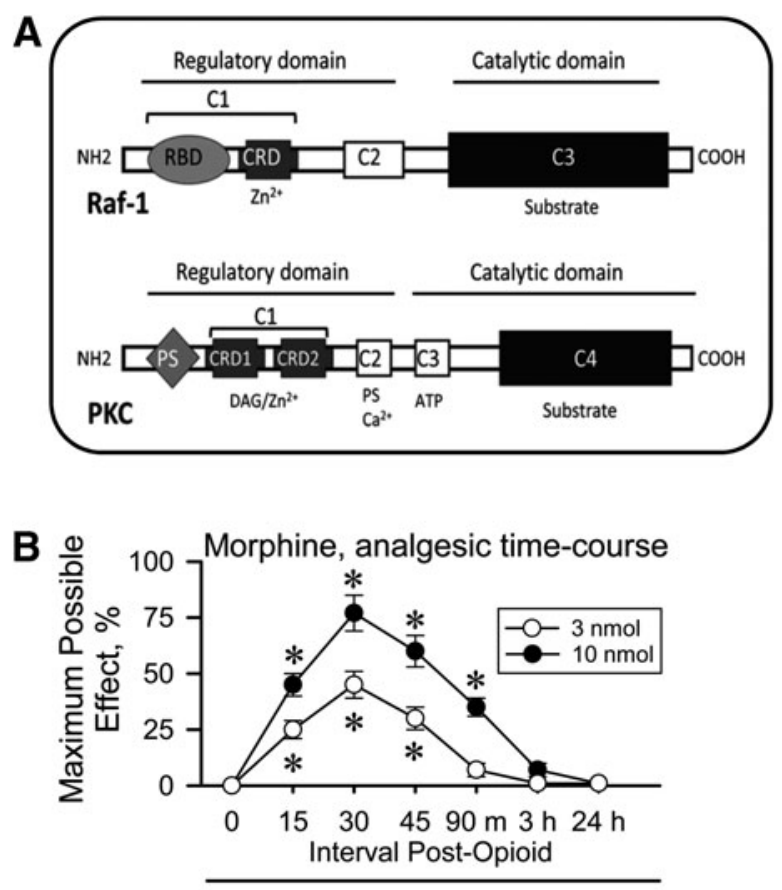

C
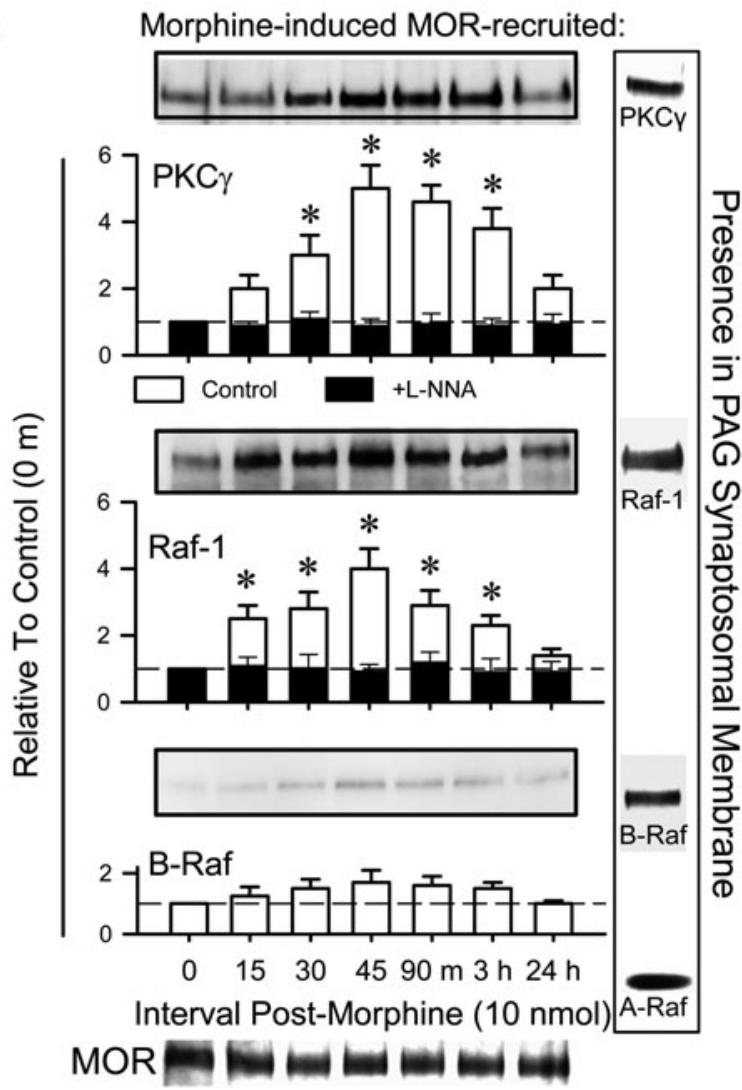
Morphine also increased the MOR association with the regulators and effectors of Raf-1 activity, such as Ras, Rap1, and ERK1/2. During the time course of morphine antinociception, MOR-associated ERK1/2 became progressively phosphorylated, suggesting its activation in this compartment (Fig. 2). All of these proteins reached and left the MOR with kinetics similar to that of Raf-1, suggesting that they were recruited as a functional complex.

The morphine-induced MOR-PKC $\gamma$ association depends on nNOS-provided free zinc ions (32). Accordingly, in vivo administration of L-NNA, an nNOS inhibitor, prevented morphine from stimulating this MOR-PKC $\gamma$ association. This treatment also avoided MOR association with Ras, Rap1, Raf1, and ERK1/2 (Figs. 1 and 2). Comparable results were obtained with in vivo administration of another $\mathrm{nNOS}$ inhibitor, NG-nitro-L-arginine methyl ester (L-NAME, $25 \mathrm{nmol}$ per mouse) (not shown). Thus, NO is required for morphine to recruit these proteins into the MOR environment. The GEF activators of Ras that contain DAG-binding CRD (30), RasGRP2 and RasGRP3, are present in mouse PAG synaptosomes. However, morphine failed to promote their association with the MOR (Fig. 2).

\section{HINT1 mediates the binding of Raf-1 to the MOR C-terminus}

The MOR-associated HINT1 protein recruits several signaling proteins to morphine-activated MORs [e.g., Akt, nNOS, and $\operatorname{PKC} \gamma(32,33,36)]$, and this protein is also essential in the MOR association with Ras/Raf-1/ERK1/2. Raf-1 and PKC $\gamma$ are present in PAG synaptosomes from mice in which the HINT1 gene has been disrupted. However, in those mice, morphine failed to stimulate the MOR association with Raf-1 (Fig. 3), Ras, Rap1, or ERK1/2 (data not shown).

\section{Morphine-induced recruitment of Raf-1 to MOR: role of the nNOS/NO/zinc pathway and of the Raf-1 CRD}

Morphine activates nNOS via the MOR/PI3K/Akt pathway (36) and promotes PKC $\gamma$-HINT1 association through free zinc ions (32). We set up an experiment to gain evidence that morphine promotes the NO-mediated release of zinc from endogenous stores. Thus, the application of morphine to mouse brain slices increased fluorescent signals associated with the increase of free zinc ions. This effect was reduced by the antagonist of MOR naloxone and also by the inhibition of nNOS activity (Fig. 4). The effects of ICV morphine on MORassociated proteins persisted during the ex vivo analysis procedure, which requires approximately $24 \mathrm{~h}$ at $4^{\circ} \mathrm{C}$, thus indicating their stability.

The role of zinc ions in these protein interactions was then assayed in membranes derived from PAG synaptosomes. Initially, the zinc ions were incubated with the membranes for $4 \mathrm{~h}$ at the same temperature as that used for the ex vivo assays, $4^{\circ} \mathrm{C}$. Free zinc ions were then removed by centrifugation and washing, the membranes were solubilised, and the MORs were immunoprecipitated. We observed that the addition of zinc increased the association of MOR, not only with PKC $\gamma$ but also with Raf-1. This was observed over a wide range of zinc ion concentrations, from mid-nanomolar concentrations to a maximum at low-micromolar concentrations (Fig. 5A). To optimize these immunosignals over those of the controls ob-

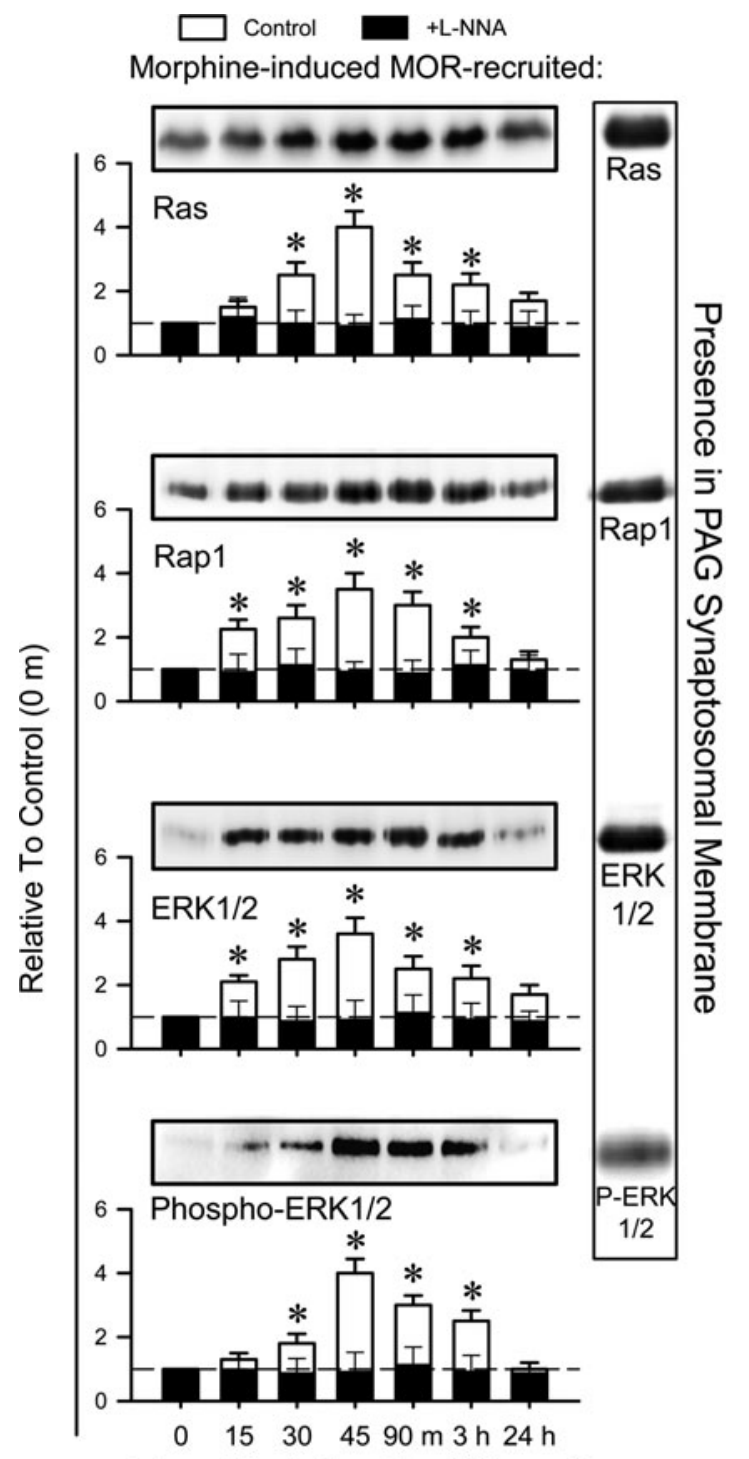

Interval Post-Morphine (10 nmol)

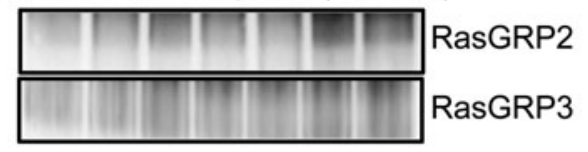

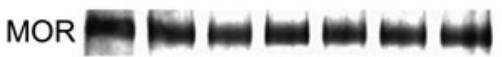

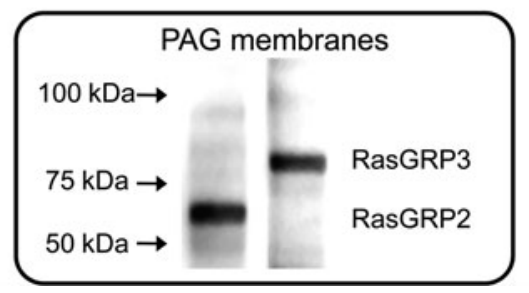

FIG. 2. Morphine recruits Ras and Rap1, as well as ERK1/ 2, to the MOR: effect of nNOS inhibition. ICV injection of 10 nmol morphine to mice was followed by ex vivo analysis of the MOR association with Ras, Rap1, ERK1/2, and activated ERK1/2 in the midbrain PAG structure. Open bars, control mice; solid bars, mice receiving L-NNA. Insets: PAG synaptosomal Ras $(21 \mathrm{kDa}), \operatorname{Rap} 1(21 \mathrm{kDa})$, ERK1/2 (42$44 \mathrm{kDa})$, activated ERK1/2, RasGRP2 (69 kDa), and RasGRP3 $(78 \mathrm{kDa})$. Details are as in the legend to Fig. 1. 

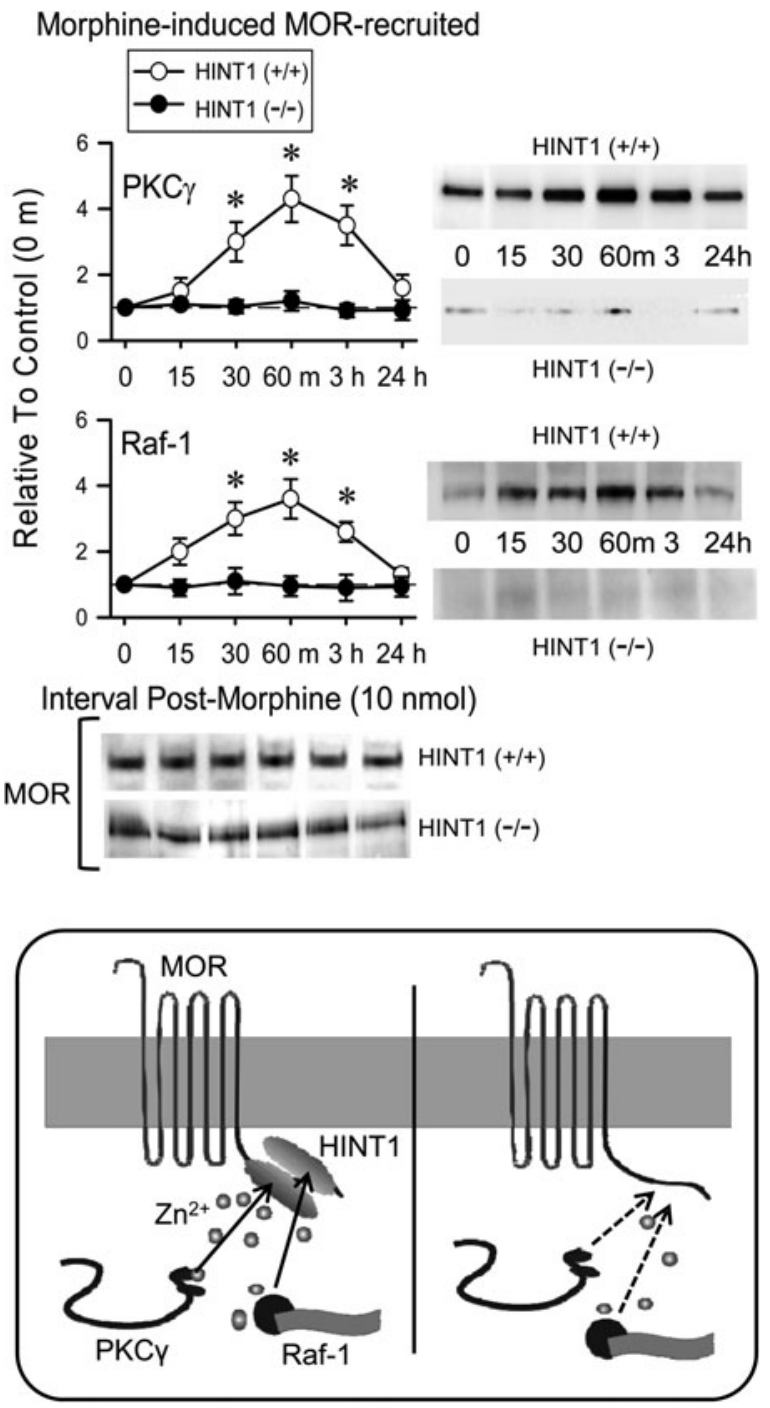

FIG. 3. MOR-associated HINT1 mediates the morphineinduced binding of Raf-1. HINT1 $(+/+)$ and $(-/-) 129 \mathrm{SvJ}$ mice received ICV $10 \mathrm{nmol}$ morphine. At intervals after injection, groups of four mice were killed, and their PAGs were pooled for the study of MOR association with Raf- 1 and PKC $\gamma$. The assays were repeated twice. Representative blots are shown. Further details are in the legend to Fig. 1. Diagram: relevance of free zinc in Raf- 1 and PKC $\gamma$ CRD binding to HINT1 homodimer at the MOR C-terminus.

tained without added zinc, this part of the study was carried out by using micromolar concentrations of the metal ion. In doing so, we observed that zinc also recruited Ras, Rap1, and ERK1/2 to the MOR environment, probably forming a preexisting complex with Raf-1 (Fig. 5B). Afterward, the time course to promote MOR-Raf-1 association was determined at $22^{\circ} \mathrm{C}$ in $3 \mu \mathrm{M}$ zinc. In these conditions, zinc promoted the association of Raf- 1 and PKC $\gamma$ with MOR in the first 5 min of incubation, and these associations were maximal after about $15 \mathrm{~min}$. As expected, the heavy-metal chelator TPEN blocked such associations (Fig. 5C). Interestingly, $15 \mathrm{~min}$ after the start of the incubation, the buffering/muffling capacity of the tissue reduced the concentration of free zinc to almost one third [after centrifugation of the samples, the supernatant was re- covered and analyzed with Zincon (34), as described in Methods]. These data indicate that zinc promoted the associations described as soon as zinc reached the target proteins. Afterward, free zinc diminished greatly, but the established associations persisted during the solubilization and analysis procedure. Therefore, in vitro assays appeared to reproduce reasonably the qualitative effects of morphine on the MORRaf-1(PKC $\gamma)$ association observed in the ex vivo analysis.

Over the range of zinc concentrations studied, nNOS (Fig. 5B) and Akt (not shown) were not recruited to the MOR. Therefore, the micromolar zinc concentrations used apparently produced no MOR aggregation, unspecific recruitment of proteins to MOR, or interference with IgG binding to the MOR. High micromolar zinc concentrations reduced the MOR association with PKC $\gamma$, Raf- 1 , and Raf-1-complexed proteins. It is then possible that these concentrations promote the arrival of third-partner proteins to displace PKC $\gamma$ and the Raf-1/ERK1/2 cassette from their association with the MOR.

Zinc ions complex the sulfydryl group in cysteine with the imidazolyl nitrogen in histidine, as well as with the carboxyl and carbonyl oxygens of glutamic and aspartic acids (24). To confirm that the Raf-1 CRD was involved in its interaction with HINT1 at the MOR, we used calphostin C, which reacts with clusters of cysteines, such as those of the PKC C1 regulatory domain, and alters their structure (12). The presence of this compound prevented the zinc-mediated association of PKC $\gamma$ and Raf-1 to the MOR-HINT1 complex (Fig. 6A). This was also true for Ras, Rap1, and ERK1/2. PKC inhibitors not affecting the integrity of the C1 CRD, such as chelerythrine or Gö7874, did not prevent the in vitro zinc-mediated MOR-Raf-1 association (not shown). The presence of TPEN reduced the formation of the zinc-dependent MOR-Raf-1 association (Fig. 6B), as well as that of Ras, Rap1, and ERK1/2 (data not shown). Calphostin and TPEN exhibit almost no dissociating activity on preformed Raf-1-MOR (PKC $\gamma$-MOR) complexes (Fig. 6C). Thus, their use in the in vitro assays mostly prevents the zinc-promoted association of target proteins, whereas these compounds produce a minor effect on the firmly established interactions.

The NO generators SNAP and NOR3 at the studied concentrations of $100 \mu \mathrm{M}$ released about 6 to 8 nmoles of free zinc ions per milligram of PAG membrane protein (Fig. 7). With about $0.8 \mathrm{mg}$ protein in a $0.5-\mathrm{ml}$ assay, the final free zinc concentration reached the low micromolar range. Thus, zinc content reasonably agrees with that described for this ion in brain tissue (45). The NO donors increased MOR-Raf-1 and MOR-PKC $\gamma$ associations and failed to recruit $\mathrm{nNOS}$ to MOR (Fig. 8). This effect was observed at long intervals ( $24 \mathrm{~h}$ ) and also at short intervals $(1 \mathrm{~h})$ of SNAP/NOR-3 incubation with the PAG membranes. The co-incubation of TPEN prevented formation of the NO-induced Raf-1- and PKC $\gamma$-MOR associations. Therefore, in PAG synaptosomal membranes, the source of zinc ions required for the MOR-Raf-1 interaction was mobilized by NO.

\section{Zinc ions support the simultaneous and direct binding of Raf-1 and PKC $\gamma$ CRDs to HINT1 protein}

In vivo, zinc ions mediate the association of Raf- 1 and PKC $\gamma$ with HINT1. By using recombinant proteins, we analyzed 

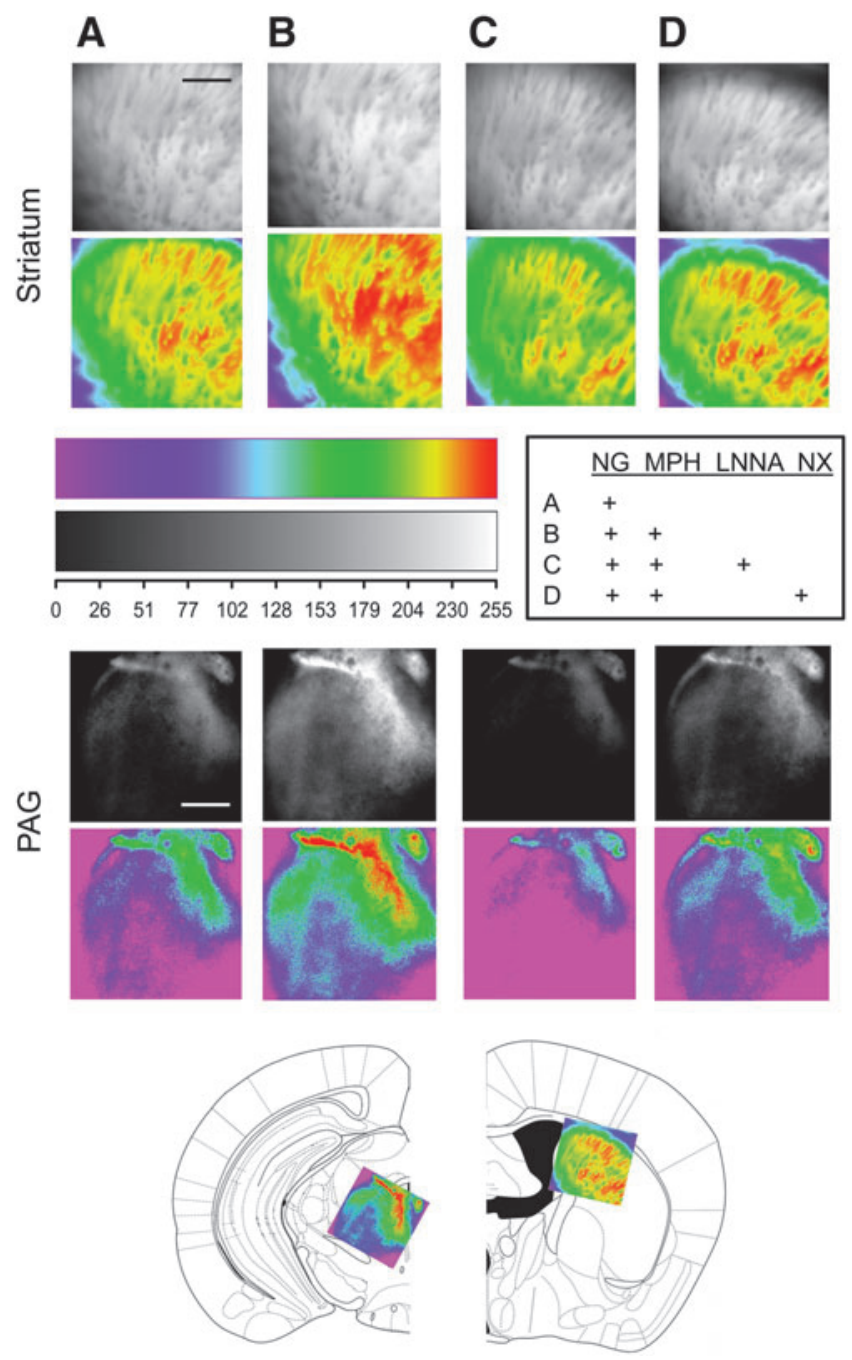

FIG. 4. Morphine induces the release of endogenous zinc by a MOR and nNOS mechanism. Mouse brain coronal slices were preloaded with $50 \mu \mathrm{M}$ cell-permeable Newport Green diacetate for $1 \mathrm{~h}$. One hemisection was treated with morphine $(10 \mu M)$, whereas the other hemisection served as a control. Zinc-related fluorescent images were taken through a $10 \times 0.4 \mathrm{HC}$ PL APO objective (excitation, 488; emission, 498-520). Striatal (interaural, $3.58 \mathrm{~mm}$; bregma, $-0.22 \mathrm{~mm}$ ) and PAG (interaural, $0.88 \mathrm{~mm}$; bregma, $-2.92 \mathrm{~mm}$ ) regions are shown. Baseline vehicle (NG), morphine treated (NG + $\mathrm{MPH})$, naloxone $(30 \mu \mathrm{M})$ treated $(\mathrm{NG}+\mathrm{MPH}+\mathrm{NX})$, and LNNA $(100 \mu M)$ treated (NG + MPH + LNNA). Images were transformed to indexed color and presented in grey and in pseudocolor. Scale: $500 \mu \mathrm{m}$. The assay was repeated 3 times on brain coronal slices derived from different mice, and the results were comparable. Representative images are shown.

Raf-1 and PKC $\gamma$ association with the HINT1 protein and the role of zinc in those interactions. First, the recombinant proteins were incubated with the heavy-metal chelator TPEN to remove any metal content. Subsequently, Raf- 1 and PKC $\gamma$ showed a zinc-dependent association with the HINT1 protein. The removal of their respective regulatory domains where the CRD resides prevented the catalytic domains of these kinases from binding to the HINT1 protein. Moreover, recombinant Ras failed to bind to the HINT1 protein, and this was explored with Ras loaded with GDP or GTP $\gamma S$ or in the presence of zinc (Fig. 9A). Conversely, PKC $\gamma$ displayed a lack of binding to Raf- 1 in the presence and absence of zinc. However, both proteins were co-precipitated simultaneously by HINT1. Increasing concentrations of $\mathrm{PKC} \gamma$ did not noticeably affect Raf-1 binding to the HINT1 protein (Fig. 9B). Therefore, HINT1 stabilizes the simultaneous zinc-dependent binding of PKC $\gamma$ and Raf-1 CRDs. The formation of this ternary complex could be of relevance in the cross-regulation of PKC $\gamma$ - and Raf-1-mediated signaling pathways.

\section{Discussion}

This study demonstrates that the neural MOR internalizes morphine signals by regulating nNOS/NO and through the oxidative release of zinc ions from intracellular stores, probably from cysteine-rich metallothioneins $(18,24)$. With NO, morphine increases the availability of neuronal free zinc (36) to the levels required to recruit PKC $\gamma$ and Raf- 1 kinases to the control of the MOR. Thus, these zinc-containing kinases behave as redox sensors in which zinc binding and release controls their binding with the HINT1 homodimer at the MOR C terminus. PKC $\gamma$ and Raf- 1 do not compete for NOand zinc-dependent binding to the HINT1 protein, suggesting their assembly into a complex in which they could influence each others' activity. In this respect, morphine promotes the sustained potentiation of NMDAR function through the activation of PKCy/Src (35) and by the activation of the Ras/ Raf-1/MEK/ERK1/2 signaling cascade $(38,50)$. Thus, their concurrence under the control of the MOR could constitute the checkpoint whereby PKC acts on Raf- 1 , bringing about ERK1/2-mediated long-term potentiation of the NMDARCaMKII function, which, in turn, operates as a negative feedback reducing MOR signalling (41). Thus, the morphineactivated Akt/nNOS/NO pathway works upstream of PKC/ Src and Raf-1/ERK1/2 pathways, providing the free zinc ions necessary to foment their cross-talk at the HINT1 protein. The discovery of this regulatory mechanism help us to understand better the steps between morphine and the activation of the ERK1/2, and it fills some of the gaps in our knowledge of NMDAR-mediated morphine analgesic tolerance.

ICV morphine recruits proteins of the MAPK cascade to the MOR [i.e., Raf-1, Ras, Rap1, and ERK1/2]. All of these regulatory proteins associate with and dissociate from MOR with similar kinetics, suggesting that they work as a functional complex. Our results indicate that Raf-1 CRD associates directly with the HINT1 protein and that it is essential to bring the ERK1/2 cascade under regulation of the MOR. Certainly, guanine nucleotide exchange factors (RasGEF) containing CRD, such as RasGRP, could also bind to the MOR-HINT1 complex in a zinc-dependent manner. However, RasGEF and Raf-1 share the binding site at $\operatorname{RasGTP}(1,43)$, and for RasGTP to bind Raf- 1 , it must first dissociate from the GEF. Consequently, Ras activators cannot mediate Raf-1/ERK1/2 translocation to the MOR-HINT1 complex. Moreover, morphine did not promote RasGRP2/3 binding to MOR. Ras itself was also discarded because RasGDP/GTP displays no binding to the HINT1 protein. The Raf isoforms A-Raf and B-Raf differ from Raf- 1 in the corresponding N-termini sequences (28). 


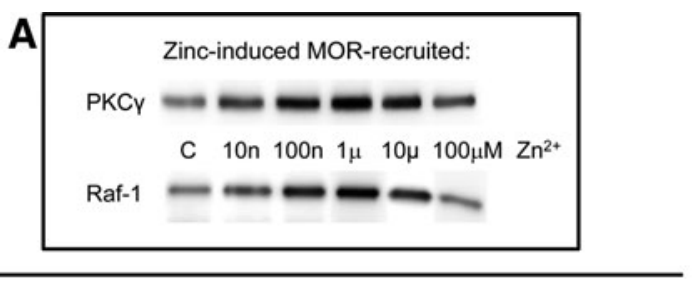

B

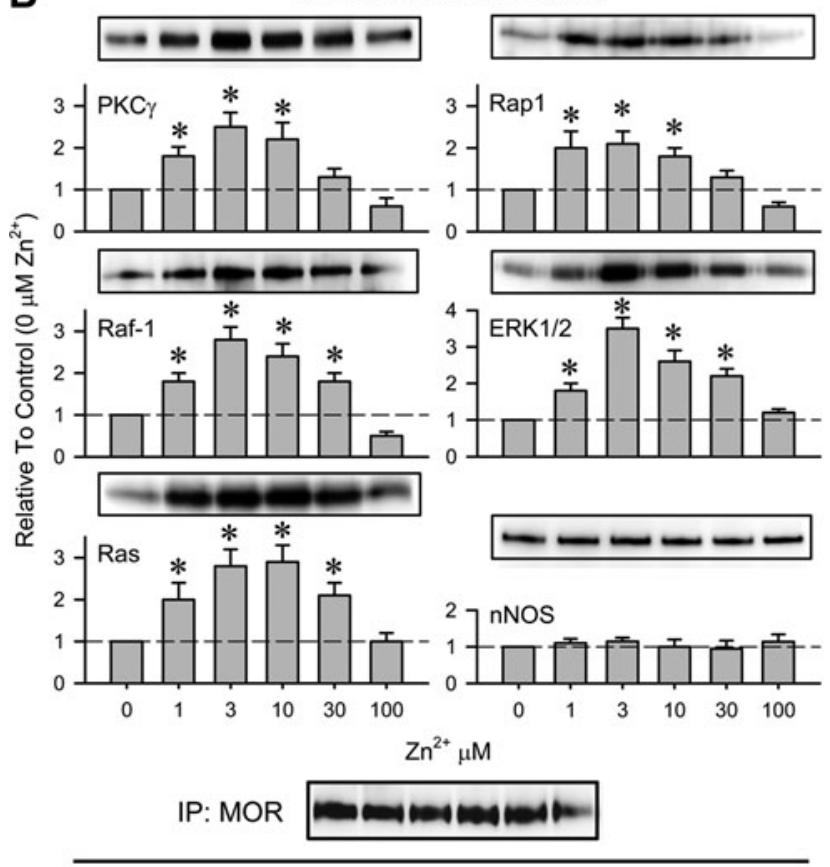

C

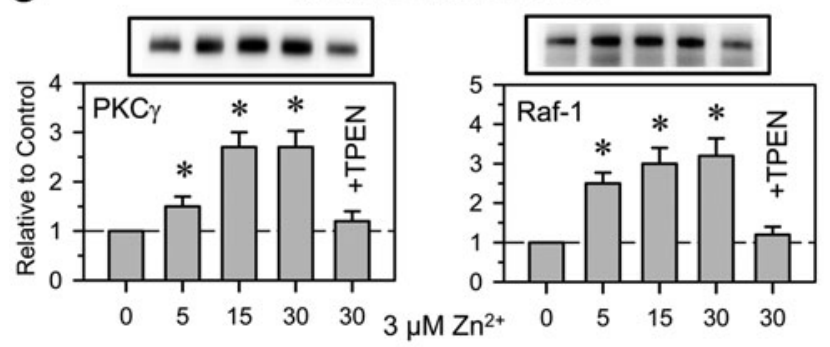

IP: MOR 200

FIG. 5. Effect of zinc on the in vitro association of the Raf-1/ERK1/2 cassette with MOR. (A, B) PAG synaptosomes were incubated with zinc chloride for $4 \mathrm{~h}$ at $4^{\circ} \mathrm{C}$. (C) The time course for the effect of $3 \mu \mathrm{M}$ zinc on MOR association with PKC $\gamma$ and Raf-1; incubation was conducted at room temperature with and without $100 \mu M$ TPEN. At the end of the procedure, free zinc was removed by three runs of centrifugation washing. Afterward, MOR was immunoprecipitated, and associated proteins were detected with the corresponding antibodies. The study was repeated 3 times on different PAG preparations. Data are expressed relative to their control (no zinc, arbitrary value of 1) as mean \pm SEM. Equal loading was determined by the MOR signals. *Significantly different from the control group (no zinc), $p<0.05$.
These differences could account for morphine mostly inducing the recruitment of Raf- 1 to the MOR.

Structurally, Raf-1 kinase exhibits considerable similarity to conventional protein kinase $C$ (see Fig. 1). Both proteins contain a regulatory amino-terminus and a carboxy-terminal catalytic domain. Additionally, a similar CRD is present within the regulatory domain of each protein, and both bind zinc ions $(27,44)$. Raf-1 CRD must contain structurally essential bound zinc ions to support RasGTP binding. However, this CRD does not interact with DAG or phorbol esters (10). The Raf- 1 N-terminus locks the kinase in an inactive conformation and contains two conserved regions, the RBD and the CRD. The RBD domain supports binding to active, GTPbound Ras (6). In addition to its RBD at the N-terminus, the CRD also plays a role in the binding of active RasGTP to Raf-1. This binding facilitates Raf-1 translocation from the cytoplasm to the plasma membrane (20) and releases the Raf-1 C3 catalytic domain from its negative regulatory interaction with the RBD-CRD regions (46).

The NO appears to be essential in the MOR-regulation of ERK1/2 signaling. In neurons, $\mathrm{NO}$ is the major mediator of calcium-dependent activation of Ras (48). However, Ras binding to Raf- 1 is insufficient by itself for Raf- 1 activation. It is postulated that after Ras binding, Raf-1 must undergo further modifications to become activated. These include tyrosine, serine/threonine phosphorylation, phospholipid binding, and interaction with other proteins (20). NO also stimulates the zinc-mediated recruitment of Raf- 1 to HINT1 at the MOR $C$ terminus, bringing the kinase under close regulation by $\mathrm{PKC} \gamma$ and probably by $\mathrm{Src}$ as well. Morphineactivated $\mathrm{PKC} \gamma$ can regulate Raf- 1 by phosphorylation, particularly at C3 serine ${ }^{497}$ and serine ${ }^{499}$ (20), greatly increasing its activity (16). Moreover, MOR-recruited PKC $\gamma$ also activates Src (35), which, in turn, could also regulate Raf-1 acting on C2 tyrosines $^{340 / 341}(20)$.

At this stage, zinc and the HINT1 protein emerge as key regulators of ERK1/2 activity by the MOR but without the need for receptor tyrosine kinase transactivation. Zinc plays a dynamic role in the regulation of PKC activity, allowing the kinase to be turned on or off (17). DAG release from PKC exposes a zinc-binding site in the C1 CRD. Zinc can now bridge the inactive kinase to the HINT1-MOR complex at the plasma membrane (32). The binding of phorbol esters/DAG to $\mathrm{C} 1 \mathrm{CRD} P K C \gamma$ releases zinc and activates the kinase. This step would promote $\operatorname{PKC} \gamma$ segregation from the $\operatorname{MOR}(17,32)$. Analogous to that described for PKC, binding of RasGTP to the Raf-1 zinc finger disrupts the zinc-mediated intramolecular binding of CRD to the catalytic domain and commences the initial steps of Raf-1 activation (20). In case this action also releases zinc, morphine-activated nNOS/NO would provide free zinc ions to recruit Raf-1 effectively to the MOR. There, activation of Raf-1 by PKC/Src phosphorylation could account for its segregation.

The HINT1 homodimer (23) supports the simultaneous binding of inactive PKC $\gamma$ and Raf-1. This ternary complex provides a mechanism for the cross-talk of two signaltransduction pathways under regulation of the MOR. There exists a functional parallelism between what is found here for HINT1 and the 14-3-3 proteins. Both are homodimers, and the 14-3-3 also acts as an adaptor, bringing together a series of proteins, Raf-1 and PKC included (42). Under 14-3-3 regulation, Raf- 1 and PKC are stabilized as inactive. PKC activation 
leads to a complex dissociation, suggesting that $14-3-3$ is a transient mediator of Raf- 1 phosphorylation and activation by PKC $(4,42)$. The 14-3-3 $\zeta$ protein binds to Raf-1 by C2 Pserine $^{259}$ and C3 P-serine ${ }^{621}$, and like HINT1, it binds the CRD as well (4). In the in vitro assays, HINT1 differs from 14-3-3 in

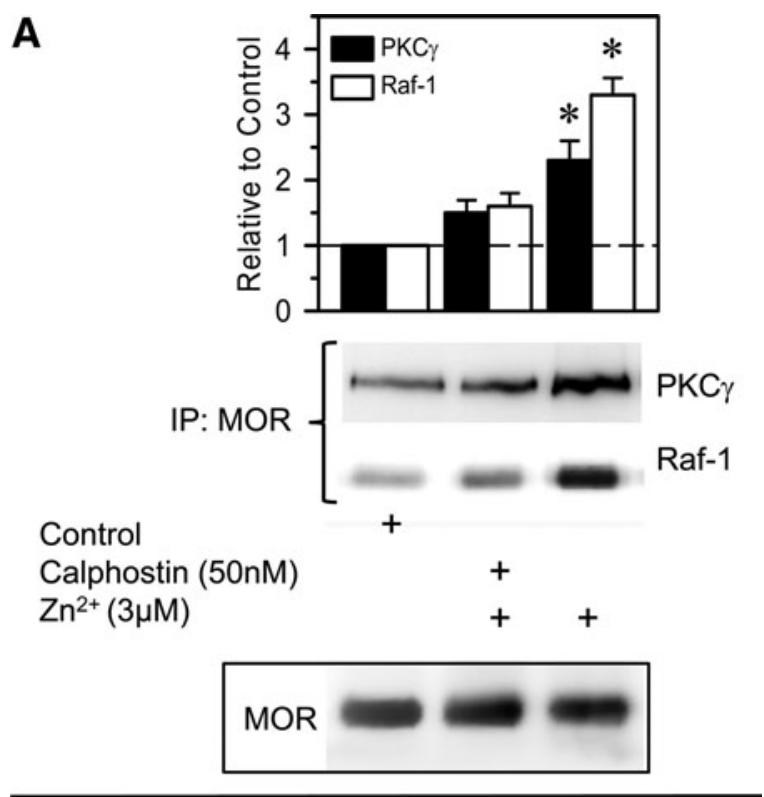

B
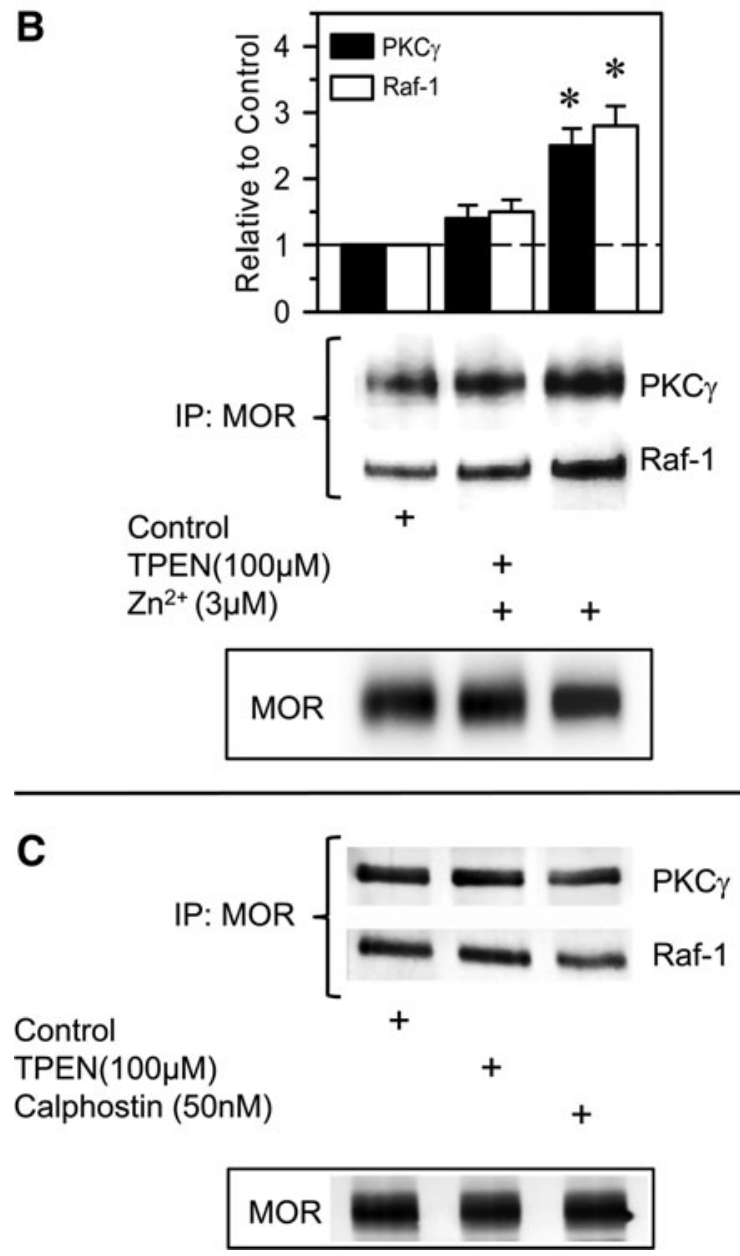

that PKC $\gamma$ and Raf-1 binding to HINT1 does not require serine phosphorylation and depends on the presence of free zinc ions. In the frame of this regulation, Rap1 should diminish the ERK1/2 activation step at the HINT1/Raf-1/PKC $\gamma$ ternary complex by reducing Ras binding to Raf- 1 .

A series of reports indicate that, whereas experimentally increased zinc levels activate PI3K/Akt $(19,21)$ and ERK1/2 pathways (39), overexpression of PTEN has opposite effects (47). PTEN is a lipid phosphatase that removes the product of PI3K, PIP3, which is required to translocate and activate Akt at the cell membrane. Zinc and PTEN are linked in that high zinc concentrations directly inhibit PTEN and then facilitate the $\mathrm{PI} 3 \mathrm{~K} / \mathrm{Akt} / \mathrm{nNOS} / \mathrm{NO}$ pathway. NO can directly activate Ras (48), and our results indicate that the NO-evoked oxidative release of zinc ions contributes to the Ras/Raf-1-mediated activation of ERK1/2. It has been reported that decreases in cellular zinc bring about low levels of ERK1/2 phosphorylation (49). Therefore, the activity of the Ras-ERK1/2 signaling pathway can be influenced by the Akt/nNOS-mediated production of $\mathrm{NO}$ and free zinc ions. Thus, high zinc concentrations acting on PTEN could simultaneously affect both signaling pathways.

It is estimated that, in presynaptic vesicles of certain glutamatergic terminals, free or chelatable zinc can reach millimolar concentrations. After physiologic stimulation, zinc ions are co-released with glutamate from presynaptic terminals, reaching high micromolar concentrations in the synaptic cleft (15). Moreover, some of these zinc ions are rapidly translocated into postsynaptic neurons through divalent cation permeable glutamate-activated channels, where they transiently reach high concentrations, mostly in the postsynaptic density region $(22,45)$. This activity confers a neurotransmitter role for the presynaptically released zinc ions, with the singularity of reaching targets inside the postsynaptic neuron. The cytosolic increase in zinc produced by its neuronal translocation, or caused by $\mathrm{nNOS} / \mathrm{NO}$ acting on intracellular stores, would be expected to influence signaling events (8). Thus, besides the MOR/PI3K/AkT/ nNOS/NO route, the coexistence of MOR and NMDAR at postsynaptic sites in PAG neurons would facilitate the access of permeated zinc ions that could regulate PKC $\gamma$ and Raf-1 binding to HINT1 (36). Nonetheless, tight control of zinc is required to maintain the redox homeostasis, and it must be rapidly buffered to reestablish the high picomolar/low nanomolar concentrations typically found in neurons $(5,7,24)$. Certainly, the zinc concentrations used in the in vitro assays do not necessarily reproduce the physiologic conditions

FIG. 6. Effect of calphostin and TPEN on zinc-dependent MOR- Raf-1 association. (A) The effect of the CRD modifier calphostin $\mathrm{C}$ was studied on the in vitro zinc-mediated recruitment of Raf-1 and PKC $\gamma$ to MOR. Calphostin $C$ was added to PAG synaptosomes $1 \mathrm{~h}$ before zinc chloride, and the incubation was continued for $4 \mathrm{~h}$ at $4^{\circ} \mathrm{C}$. (B) The heavy-metal ion chelator TPEN prevents zinc from facilitating Raf- 1 and PKC $\gamma$ binding to the MOR. (C) Effect of TPEN, $100 \mu M$, and calphostin, $50 \mathrm{nM}$, on the basal (no zinc added) association of Raf- 1 and PKC $\gamma$ with MOR in PAG membranes. Equal loading was determined by the MOR signals. *Significantly different from the control group, $p<0.05$. Details are as in the legend to Fig. 5. 

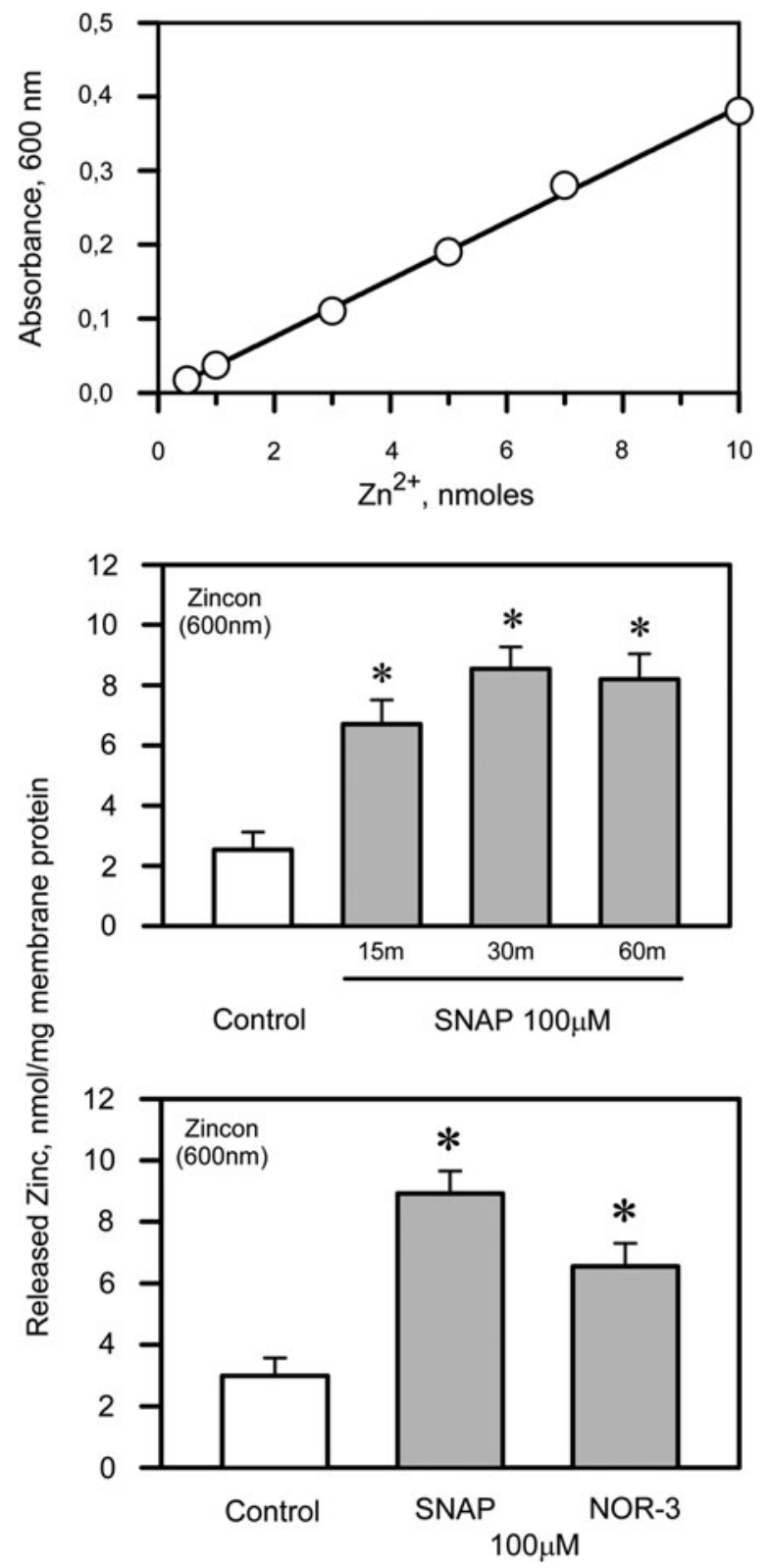

FIG. 7. SNAP and NOR-3 release endogenous zinc from PAG synaptosome membranes. SNAP and NOR-3 $(100 \mu M)$ were added to PAG membranes. The assays were conducted at RT. Upper panel: Calibration curve for Zincon detection of $\mathrm{Zn}^{2+}$. Middle panel: Time course for SNAP-induced release of endogenous zinc. Lower panel: NO donors $(100 \mu \mathrm{M})$ were incubated with PAG membranes for $30 \mathrm{~min}$. Zinc release was monitored by its complexation with the zinc chelator Zincon. The absorbance $(600 \mathrm{~nm})$ was recorded at RT on a BioChrom Ultrospec 2100 spectrophotometer (Cambridge, UK). Data are expressed as the mean \pm SEM of three independent assays. *Significantly different from the control group (without NO donor), $p<0.05$.

responsible for NO- and zinc-dependent recruitment of PKC $\gamma$ and Raf- 1 to MOR-HINT1 complex. It is more likely that such effects are achieved at mid-nanomolar concentrations of zinc. However, the use of low micromolar concentrations in vitro permitted better immunodetection and the
NO donors
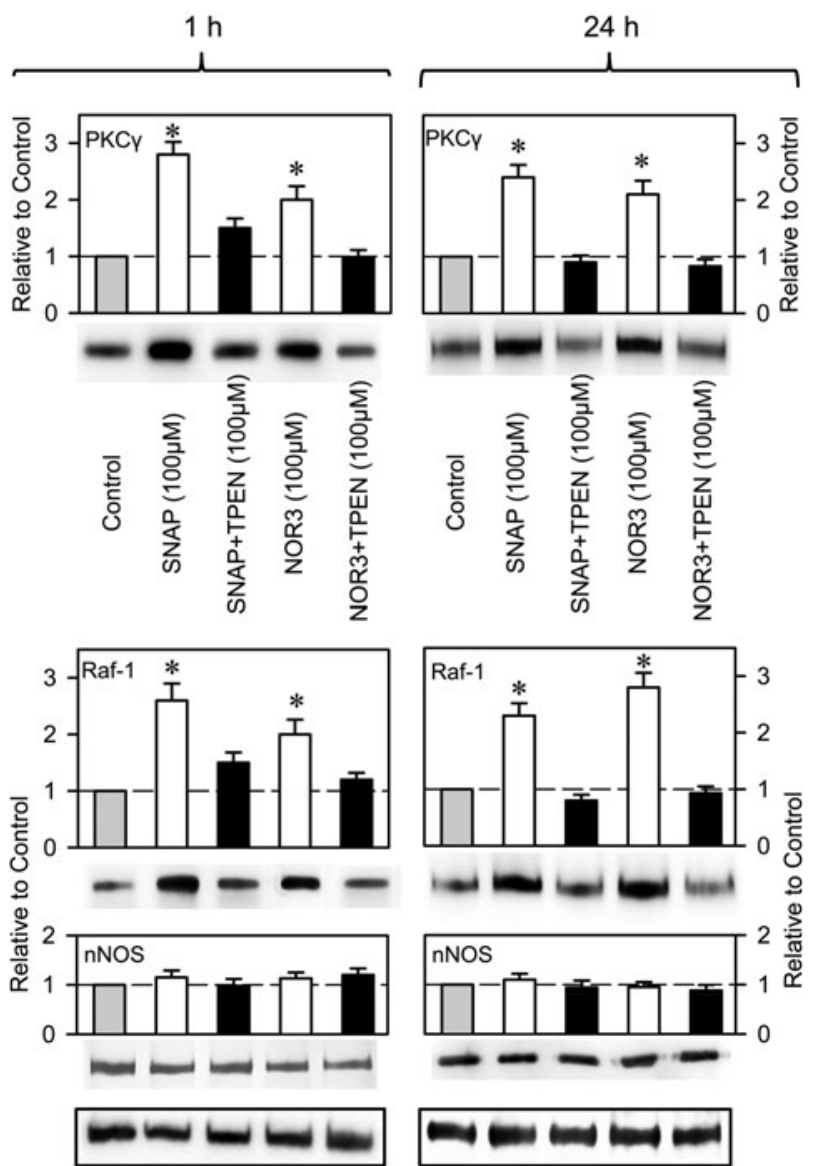

IP: MOR

FIG. 8. NO provides the zinc ions required for MOR association with Raf-1 and PKC $\gamma$. SNAP and NOR3 were incubated with PAG membranes either for $1 \mathrm{~h}$ at RT or for $24 \mathrm{~h}$ at $4^{\circ} \mathrm{C}$. The NO donors $(100 \mu \mathrm{M})$ were incubated alone or with TPEN $(100 \mu M)$. Subsequently, the influence of these treatments on the MOR association with Raf- $1, P K C \gamma$, and nNOS proteins was evaluated. The data in each column are expressed as the mean $\pm S E M$ of three independent assays. MOR signals served to control loading. *Significantly different from the control group, $p<0.05$.

pharmacologic characterization of the signaling proteins under study.

In summary, morphine promotes the recruitment of the Ras/Raf-1/ERK1/2 signaling cassette, and of PKC $\gamma$, to the HINT1-MOR complex. The CRDs in the $\mathrm{N}$ terminal regulatory region of the Raf- 1 and $P K C \gamma$ serine/threonine kinases are those implicated in their zinc-dependent binding to HINT1 protein. The homodimeric structure of HINT1 supports the simultaneous binding of these kinases, enabling the cross-talk of these two signaling pathways under the regulation of the MOR. In this compartment, PKC $\gamma$ exerts a fine degree of control over Raf- 1 and the subsequent activation of ERK1/2. The morphine-activated MOR/PI3K/Akt/nNOS pathway provides the NO necessary to release the free zinc ions implicated in the binding of PKC $\gamma$ and Raf- 1 to the MORHINT1 complex. Thus, our data unveil a redox mechanism by which the MOR, via NO and zinc ions, regulates the ERK1/2 cascade in neural cells. 

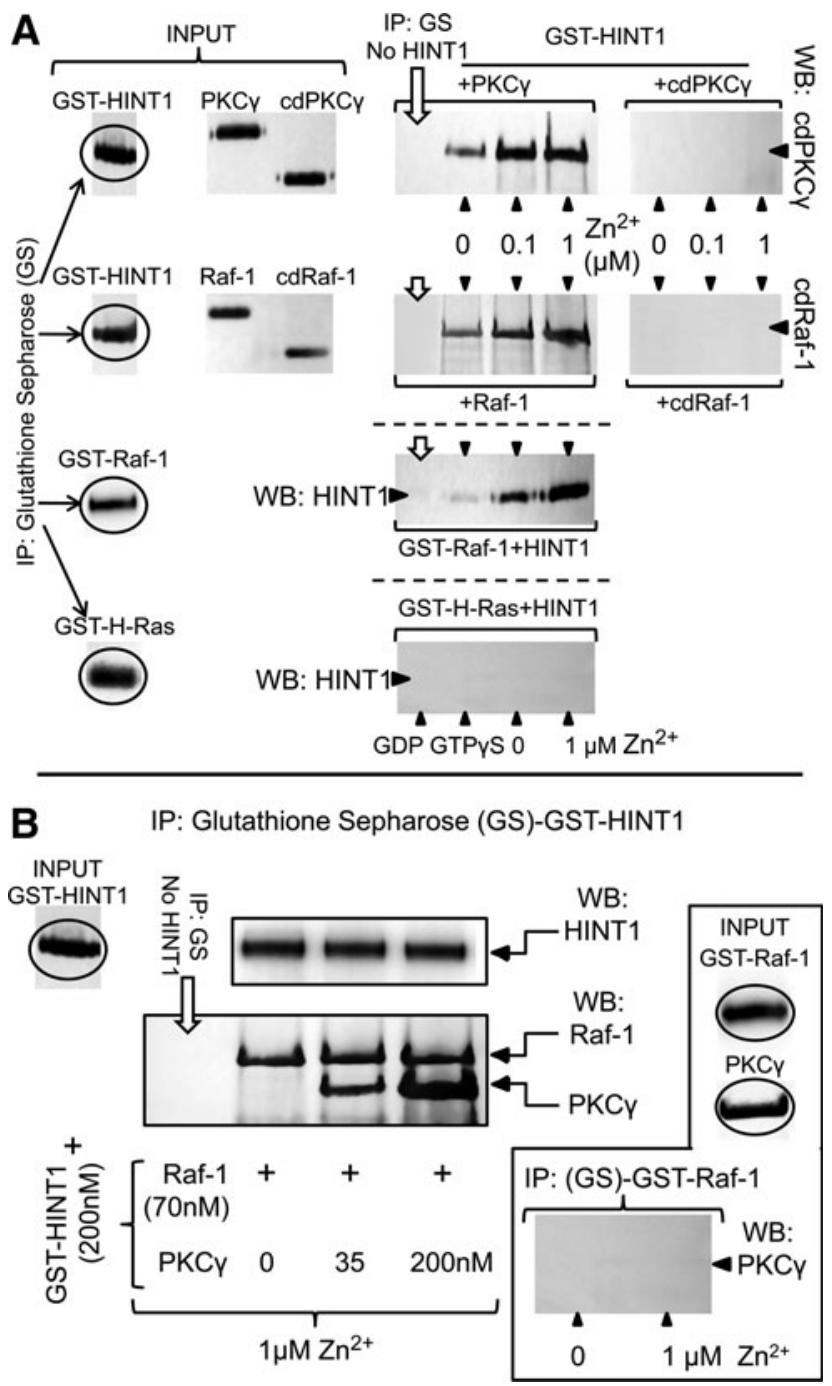

FIG. 9. Raf-1 and PKC $\gamma$ CRD bind via zinc to HINT1. Formation of a ternary complex. (A) Interaction of recombinant proteins HINT1, PKC $\gamma$, and Raf- 1 . The HINT1 protomer was used at $200 \mathrm{nM}$, whereas PKC $\gamma$ and Raf-1 [whole sequence and catalytic domain (cd)] were used at $100 \mathrm{nM}$. After TPEN zinc removal, proteins were incubated alone (negative control) or with the GST-tagged protein. The influence of added zinc was evaluated. After incubation, glutathione sepharose (GS) was added to the incubation mixture; the proteins were resolved by SDS-PAGE chromatography and analyzed with Western blotting. A similar study of association was conducted between the recombinant proteins Ras and HINT1. (B) HINT1 mediates the formation of a ternary complex with Raf- 1 and PKC $\gamma$. After TPEN zinc removal, the whole sequences of Raf- 1 and PKC $\gamma$ showed no interaction with or without added zinc. The binding of Raf-1 to the HINT1 protein was not reduced, whereas the HINT1-PKC $\gamma$ association increased.

\section{Acknowledgments}

This research was supported by the Instituto de Salud Carlos III PI08-0417 (PSB) and PS09/00332 (JG). MRM is currently supported by a CIBERSAM contract. ETM is a predoctoral fellow supported by the Spanish Ministry of Science and In- novation. We thank Concha Bailón and Beatriz Fraile for their excellent technical assistance.

\section{Author Disclosure Statement}

The authors declare that, except for income received from our primary employer, "Ministerio de Ciencia y Tecnología," no financial support or compensation has been received from any individual or corporate entity over the past 3 years for research or professional service, and no personal financial holdings could be perceived as constituting a potential conflict of interest.

\section{References}

1. Buday L and Downward J. Many faces of Ras activation. Biochim Biophys Acta 1786: 178-187, 2008.

2. Chen L and Huang LY. Sustained potentiation of NMDA receptor-mediated glutamate responses through activation of protein kinase C by a $\mu$ opioid. Neuron 7: 319-326, 1991.

3. Chen $Y$ and Sommer C. The role of mitogen-activated protein kinase (MAPK) in morphine tolerance and dependence. Mol Neurobiol 40: 101-107, 2009.

4. Clark GJ, Drugan JK, Rossman KL, Carpenter JW, RogersGraham K, Fu H, Der CJ, and Campbell SL. 14-3-3 zeta negatively regulates raf- 1 activity by interactions with the Raf-1 cysteine-rich domain. J Biol Chem 272: 20990-20993, 1997.

5. Colvin RA, Holmes WR, Fontaine CP, and Maret W. Cytosolic zinc buffering and muffling: their role in intracellular zinc homeostasis. Metallomics 2: 306-317, 2010.

6. Daub M, Jockel J, Quack T, Weber CK, Schmitz F, Rapp UR, Wittinghofer A, and Block C. The RafC1 cysteine-rich domain contains multiple distinct regulatory epitopes which control Ras-dependent Raf activation. Mol Cell Biol 18: 66986710, 1998.

7. Erickson JC, Hollopeter G, Thomas SA, Froelick GJ, and Palmiter RD. Disruption of the metallothionein-III gene in mice: analysis of brain zinc, behavior, and neuron vulnerability to metals, aging, and seizures. J Neurosci 17: 1271-1281, 1997.

8. Frederickson CJ, Koh JY, and Bush AI. The neurobiology of zinc in health and disease. Nat Rev Neurosci 6: 449-462, 2005.

9. Garzón J, Rodríguez-Muñoz M, and Sánchez-Blázquez P. Do pharmacological approaches that prevent opioid tolerance target different elements in the same regulatory machinery? Curr Drug Abuse Rev 1: 222-238, 2008.

10. Ghosh S, Xie WQ, Quest AF, Mabrouk GM, Strum JC, and Bell RM. The cysteine-rich region of raf-1 kinase contains zinc, translocates to liposomes, and is adjacent to a segment that binds GTP-ras. J Biol Chem 269: 10000-10007, 1994.

11. Ji RR, Gereau RW, Malcangio M, and Strichartz GR. MAP kinase and pain. Brain Res Rev 60: 135-148, 2009.

12. Kazanietz MG, Lewin NE, Bruns JD, and Blumberg PM. Characterization of the cysteine-rich region of the Caenorhabditis elegans protein Unc-13 as a high affinity phorbol ester receptor: analysis of ligand-binding interactions, lipid cofactor requirements, and inhibitor sensitivity. J Biol Chem 270: 10777-10783, 1995

13. Kieffer BL and Gaveriaux-Ruff C. Exploring the opioid system by gene knockout. Prog Neurobiol 66: 285-306, 2002.

14. Kissin I, Bright CA, and Bradley EL Jr. The effect of ketamine on opioid-induced acute tolerance: can it explain reduction 
of opioid consumption with ketamine-opioid analgesic combinations? Anesth Analg 91: 1483-1488, 2000.

15. Knott $A B$ and Bossy-Wetzel E. Nitric oxide in health and disease of the nervous system. Antioxid Redox Signal 11: 541554, 2009.

16. Kolch W, Heidecker G, Kochs G, Hummel R, Vahidi H, Mischak H, Finkenzeller G, Marme D, and Rapp UR. Protein kinase $\mathrm{C}$ alpha activates RAF-1 by direct phosphorylation. Nature 364: 249-252, 1993.

17. Korichneva I. Zinc dynamics in the myocardial redox signaling network. Antioxid Redox Signal 8: 1707-1721, 2006.

18. Kroncke KD. Zinc finger proteins as molecular targets for nitric oxide-mediated gene regulation. Antioxid Redox Signal 3: 565-575, 2001.

19. Kroncke KD and Klotz LO. Zinc fingers as biologic redox switches? Antioxid Redox Signal 11: 1015-1027, 2009.

20. Leicht DT, Balan V, Kaplun A, Singh-Gupta V, Kaplun L, Dobson M, and Tzivion G. Raf kinases: function, regulation and role in human cancer. Biochim Biophys Acta 1773: 11961212, 2007.

21. Leslie NR. The redox regulation of PI 3-kinase-dependent signaling. Antioxid Redox Signal 8: 1765-1774, 2006.

22. Li Y, Hough CJ, Suh SW, Sarvey JM, and Frederickson CJ. Rapid translocation of $\mathrm{Zn}(2+)$ from presynaptic terminals into postsynaptic hippocampal neurons after physiological stimulation. J Neurophysiol 86: 2597-2604, 2001.

23. Lima CD, Klein MG, Weinstein IB, and Hendrickson WA. Three-dimensional structure of human protein kinase $C$ interacting protein 1 , a member of the HIT family of proteins. Proc Natl Acad Sci U S A 93: 5357-5362, 1996.

24. Maret W. Zinc coordination environments in proteins as redox sensors and signal transducers. Antioxid Redox Signal 8: 1419-1441, 2006.

25. Moodie SA, Willumsen BM, Weber MJ, and Wolfman A. Complexes of Ras.GTP with Raf-1 and mitogen-activated protein kinase kinase. Science 260: 1658-1661, 1993.

26. Mott HR, Carpenter JW, Zhong S, Ghosh S, Bell RM, and Campbell SL. The solution structure of the Raf-1 cysteinerich domain: a novel ras and phospholipid binding site. Proc Natl Acad Sci U S A 93: 8312-8317, 1996.

27. Newton AC. Protein kinase C: structural and spatial regulation by phosphorylation, cofactors, and macromolecular interactions. Chem Rev 101: 2353-2364, 2001.

28. Okada T, Hu CD, Jin TG, Kariya K, Yamawaki-Kataoka Y, and Kataoka $T$. The strength of interaction at the Raf cysteine-rich domain is a critical determinant of response of Raf to Ras family small GTPases. Mol Cell Biol 19: 60576064, 1999

29. Polakiewicz RD, Schieferl SM, Dorner LF, Kansra V, and Comb MJ. A mitogen-activated protein kinase pathway is required for mu-opioid receptor desensitization. J Biol Chem 273: 12402-12406, 1998.

30. Quilliam LA, Rebhun JF, and Castro AF. A growing family of guanine nucleotide exchange factors is responsible for activation of Ras-family GTPases. Prog Nucleic Acid Res Mol Biol 71: 391-444, 2002.

31. Rodríguez-Muñoz M, de la Torre-Madríd E, SánchezBlázquez P, and Garzón J. Morphine induces endocytosis of neuronal mu-opioid receptors through the sustained transfer of Galpha subunits to RGSZ2 proteins. Mol Pain 3: 19, 2007.

32. Rodríguez-Muñoz M, de IT-M, Sánchez-Blázquez P, Wang JB, and Garzón J. NMDAR-nNOS generated zinc recruits
PKCgamma to the HINT1-RGS17 complex bound to the C terminus of Mu-opioid receptors. Cell Signal 20: 1855-1864, 2008.

33. Rodríguez-Muñoz M, Sánchez-Blázquez $\mathrm{P}$, Vicente-Sánchez A, Bailón C, Martín-Aznar B, and Garzón J. The histidine triad nucleotide-binding protein 1 supports mu-opioid receptorglutamate NMDA receptor cross-regulation. Cell Mol Life Sci DOI: 10.1007 s00018-s0100598-x, 2010.

34. Sabel CE, Neureuther JM, and Siemann S. A spectrophotometric method for the determination of zinc, copper, and cobalt ions in metalloproteins using Zincon. Anal Biochem 397: 218-226, 2010.

35. Sánchez-Blázquez $\mathrm{P}$, Rodríguez-Muñoz M, de la Torre-Madríd E, and Garzón J. Brain-specific G $\alpha z$ interacts with Src tyrosine kinase to regulate $\mathrm{Mu}$-opioid receptor-NMDAR signaling pathway. Cell Signal 21: 1444-1454, 2009.

36. Sánchez-Blázquez P, Rodríguez-Muñoz M, and Garzón J. Mu-opioid receptors transiently activate the AktnNOS pathway to produce sustained potentiation of PKCmediated NMDAR-CaMKII signaling. PLoS One 5: e11278, 2010.

37. Sánchez-Blázquez P, Rodríguez-Muñoz M, Montero C, de la Torre-Madrid E, and Garzón J. Calcium/calmodulindependent protein kinase II supports morphine antinociceptive tolerance by phosphorylation of glycosylated phosducin-like protein. Neuropharmacology 54: 319-330, 2008.

38. Schmidt H, Schulz S, Klutzny M, Koch T, Handel M, and Hollt V. Involvement of mitogen-activated protein kinase in agonist-induced phosphorylation of the mu-opioid receptor in HEK 293 cells. J Neurochem 74: 414-422, 2000.

39. Seo SR, Chong SA, Lee SI, Sung JY, Ahn YS, Chung KC, and Seo JT. Zn2 + -induced ERK activation mediated by reactive oxygen species causes cell death in differentiated PC12 cells. J Neurochem 78: 600-610, 2001.

40. Su T, Suzui M, Wang L, Lin CS, Xing WQ, and Weinstein IB. Deletion of histidine triad nucleotide-binding protein $1 /$ PKC-interacting protein in mice enhances cell growth and carcinogenesis. Proc Natl Acad Sci U S A 100: 78247829, 2003.

41. Trujillo KA and Akil $\mathrm{H}$. Inhibition of morphine tolerance and dependence by the NMDA receptor antagonist MK-801. Science 251: 85-87, 1991.

42. Van Der Hoeven PC, Van Der Wal JC, Ruurs P, Van Dijk MC, and Van BJ. 14-3-3 isotypes facilitate coupling of protein kinase C-zeta to Raf-1: negative regulation by 14-3-3 phosphorylation. Biochem J 345: 297-306, 2000.

43. Vetter IR and Wittinghofer A. The guanine nucleotide-binding switch in three dimensions. Science 294: 1299-1304, 2001.

44. Warne PH, Viciana PR, and Downward J. Direct interaction of Ras and the amino-terminal region of Raf-1 in vitro. Nature 364: 352-355, 1993.

45. Weiss JH, Sensi SL, and Koh JY. Zn(2+): a novel ionic mediator of neural injury in brain disease. Trends Pharmacol Sci 21: 395-401, 2000.

46. Winkler DG, Cutler RE Jr, Drugan JK, Campbell S, Morrison $\mathrm{DK}$, and Cooper JA. Identification of residues in the cysteine-rich domain of Raf- 1 that control Ras binding and Raf-1 activity. J Biol Chem 273: 21578-21584, 1998.

47. Wu W, Wang X, Zhang W, Reed W, Samet JM, Whang YE, and Ghio AJ. Zinc-induced PTEN protein degradation through the proteasome pathway in human airway epithelial cells. J Biol Chem 278: 28258-28263, 2003.

48. Yun HY, Gonzalez-Zulueta M, Dawson VL, and Dawson TM. Nitric oxide mediates $N$-methyl-D-aspartate receptor- 
induced activation of p21ras. Proc Natl Acad Sci U S A 95: 5773-5778, 1998.

49. Zago MP, Mackenzie GG, Adamo AM, Keen CL, and Oteiza PI. Differential modulation of MAP kinases by zinc deficiency in IMR-32 cells: role of $\mathrm{H}(2) \mathrm{O}(2)$. Antioxid Redox Signal 7: 1773-1782, 2005.

50. Zhu JJ, Qin Y, Zhao M, Van AL, and Malinow R. Ras and Rap control AMPA receptor trafficking during synaptic plasticity. Cell 110: 443-455, 2002.

Address correspondence to: Prof. Javier Garzón Instituto Cajal, CSIC

Avd. Dr. Arce 37 28002 Madrid Spain

E-mail: jgarzon@cajal.csic.es

Date of first submission to ARS Central, July 21, 2010; date of final revised submission, January 10, 2011; date of acceptance, January 14, 2011.

\section{Abbreviations Used}

$\mathrm{CRD}=$ cysteine-rich domain

$\mathrm{DAG}=$ diacylglycerol

$\mathrm{ERK}=$ extracellular signal-regulated kinase

$\mathrm{GPCR}=\mathrm{G}$ protein-coupled receptor

HINT1 $=$ histidine triad nucleotide-binding protein 1

$\mathrm{ICV}=$ intracerebroventricular

$\mathrm{MAPK}=$ mitogen-activated protein kinase

$\mathrm{MOR}=$ mu opioid receptor

NMDAR $=N$-methyl-D-aspartate receptor

$\mathrm{nNos}=$ neural nitric oxide synthase

$\mathrm{NO}=$ nitric oxide

NOR-3 = ( \pm )-(E)-ethyl-2-[(E)-hydroxyimino]-5-nitro3-hexeneamide

$\mathrm{PAG}=$ periaqueductal gray matter

$\mathrm{PKC}=$ protein kinase $\mathrm{C}$

Rap/Ras $=$ low-molecular-weight $\mathrm{G}$ proteins

$\mathrm{RBD}=$ Ras-binding domain

$\mathrm{SNAP}=(\mathrm{S})$-nitroso- $\mathrm{N}$-acetylpenicillamine

Src $/$ Fyn $=$ nonreceptor tyrosine kinase

TPEN $=N, N, N^{\prime}, N^{\prime}$-tetrakis(2-pyridylmethyl) ethylenediamine 
